\title{
Social facilitation for conservation planning: understanding fairy tern behavior and site selection in response to conspecific audio-visual cues
}

\author{
C. N. Greenwell ${ }^{1,2, *}$, K. S. Born ${ }^{3}$, R. Admiraal ${ }^{4}$, A. Hodgson ${ }^{1,2}$, J. N. Dunlop ${ }^{1,3}$, \\ N. R. Loneragan ${ }^{1,2}$ \\ ${ }^{1}$ Conservation and Environmental Sciences, College of SHEE, Murdoch University, 90 South Street, Murdoch, \\ Western Australia 6150, Australia \\ ${ }^{2}$ Centre for Sustainable Aquatic Ecosystems, Harry Butler Institute, Murdoch University, 90 South Street, Murdoch, \\ Western Australia 6150, Australia \\ ${ }^{3}$ Conservation Council of Western Australia, Lotteries West House, 2 Delhi Street, West Perth, Western Australia 6150, Australia \\ ${ }^{4}$ Victoria University of Wellington, School of Mathematics and Statistics, Kelburn Parade, Wellington 6012, New Zealand
}

\begin{abstract}
Simulated social facilitation techniques (e.g. decoys and call playbacks) are commonly used to attract seabirds to restored and artificially created nesting habitats. However, a lack of social stimuli and conspecific cueing at these habitats may limit the use of these sites, at least in the short term. Therefore, testing the effectiveness of simulated audio-visual cues for attracting gregarious birds is important for conservation planning. In this study, we (1) assessed whether call playback and decoys were associated with an increased likelihood of Australian fairy terns Sternula nereis nereis visiting potentially suitable nesting habitats; (2) tested their behavioral response to different cues; and (3) documented whether social facilitation had the potential to encourage colony establishment. A full cross-over study design consisting of all possible pairings of decoy and call playback treatments (control [no attractants], decoys, call playback, both decoys and playback), allocated as part of a random block design, was undertaken at 2 sites. Linear modeling suggested that call playback was important in explaining the time spent aerial prospecting as well as the maximum number of fairy terns aerial prospecting, although this only appeared to be the case for 1 of the 2 sites. Decoys, on the other hand, did not appear to have any effect on time spent aerial prospecting. The results from this study suggest that audio cues have the potential to encourage site selection by increasing social stimuli, but attractants may be required over several breeding seasons before colonies are established.
\end{abstract}

KEY WORDS: Conservation behavior $\cdot$ Laridae $\cdot$ Managed site $\cdot$ Seabird restoration $\cdot$ Sensory ecology

\section{INTRODUCTION}

Coastal systems, with their complex mosaic of shallow-water habitats and shorelines of varying geomorphology, support rich floral and faunal communities worldwide and are important breeding and feeding sites for an array of birds. Despite the impor-

${ }^{*}$ Corresponding author: c.greenwell@murdoch.edu.au tance of these environments, growing human populations and the associated demand for housing, ports, marinas, and recreational amenities have led to significant reductions in habitat and resource availability, driving population declines among coastal bird communities (Yasué et al. 2007, Pakanen et al. 2014).

(1) The authors 2021. Open Access under Creative Commons by Attribution Licence. Use, distribution and reproduction are unrestricted. Authors and original publication must be credited. 
The threats to coastal birds during the breeding season are numerous and include both climate- and anthropogenic-driven pressures. Managed sites, where interventions such as habitat enhancement and predator control are undertaken to improve breeding success (Greenwell et al. 2019a, 2020), may become increasingly important within urban environments (e.g. Jenniges \& Plettner 2008, Fujita et al. 2009). However, remedial works and site engineering can be costly (Hecht \& Melvin 2009), and restored or artificially created sites may not be immediately utilized because of an absence of social stimuli and conspecific cueing (Boulinier et al. 1996).

Given the potential for colony- and nest-site selection to affect individual fitness, birds use complex strategies to select breeding sites, including environmental and social cues (Cody 1985). Among gregarious birds, social facilitation (i.e. where the behavior of one individual increases the probability of other animals engaging in that same behavior) at colony sites is often used to assess habitat quality and an individual's chance of reproductive success, these being proximate cues for nest site selection (Gochfeld 1980, Boulinier et al. 1996, Kress 1997, Danchin et al. 1998). Social facilitation behavior may be especially important among coastal gulls and terns, which are known to periodically shift colony sites between breeding attempts (Dunlop 1987, Gochfeld \& Burger 1992, Dunlop \& Greenwell 2021).

Simulated social facilitation techniques such as the use of conspecific audio-visual cues (e.g. call playback and decoys) offer a powerful opportunity to influence animal behavior, including occupancy at restored or created habitats (James et al. 2015, Friesen et al. 2017), particularly among species like seabirds that have behavioral and life-history traits that rely on strong sensory signaling (Kress \& Nettleship 1988, Kress 1997, Friesen et al. 2017). James et al. (2015) showed that call playback could be used to manipulate the distribution of amphibians within previously unoccupied ponds, offering a habitat restoration tool for threatened species conservation. Conspecific cues have also been used to successfully restore numerous seabird colonies (e.g. roseate terns Sterna dougallii, Arctic terns S. paradisaea, and common terns $S$. hirundo; Kress 1983, 1997). When combined with appropriate habitat management and predator controls, they offer great potential to improve long-term conservation outcomes. However, the effectiveness of simulated audio-visual stimuli can vary between species (reviewed by Friesen et al. 2017). Therefore, understanding the drivers of site selection for the target species and assessing the effi- cacy of simulated social facilitation techniques is an important step for conservation planning.

The fairy tern Sternula nereis is listed as Vulnerable on the International Union for Conservation of Nature Red List because of decreasing population trends over much of its breeding range in recent decades (BirdLife International 2018, Commonwealth of Australia 2019). Fairy terns typically nest on sheltered bays, coastal lagoons, sand spits, or lacustrine islands (Higgins \& Davies 1996, Johnstone \& Storr 1998, Dunlop 2018), habitats that are also highly valued for human use. To overcome a lack of natural nesting sites and to reduce disturbance at breeding colonies, managed sites, combined with social facilitation techniques, may be an effective strategy for improving nesting success (Dunlop 2018, Greenwell et al. 2021). Social facilitation to encourage site selection at secure or managed nesting sites has been identified as a possible 'local conservation strategy' to improve population trends under the Draft $\mathrm{Na}$ tional Recovery Plan for the Australian fairy tern Sternula nereis nereis (Commonwealth of Australia 2019).

The first objective of this study was to determine whether audio-visual cues would increase the likelihood of attracting Australian fairy terns S. nereis nereis (hereafter fairy terns) to an area of potentially suitable nesting habitat, and if so, which cue would elicit the strongest behavioral response. It was hypothesized that a combination of auditory and visual cues would provoke the strongest response compared to either visual or audio cues used in isolation and control treatments. Call playback was expected to provide a strong initial cue and draw attention to the site, while decoys were likely to encourage settlement through visual cueing. Our second objective was to determine whether social facilitation had the potential to encourage fairy tern colony establishment and egg laying at 2 managed sites (Mandurah and Garden Island) in temperate south-western Australia (see Fig. 1), which are historically important nesting sites for the species.

\section{MATERIALS AND METHODS}

\subsection{Study sites}

The first study site was located in Mandurah $\left(32^{\circ} 31^{\prime} 14.24^{\prime \prime} \mathrm{S}, 115^{\circ} 43^{\prime} 0.26^{\prime \prime} \mathrm{E}\right)$ and is managed by the local government authority, the City of Mandurah. Fairy terns have a long-known history of nesting in the lower reaches of the Peel-Harvey Estuary, 
Mandurah, likely because of the abundance of potential fish prey in the system and adjacent coastal waters. For many years, fairy terns nested at the mouth of the estuary, but this land has since been developed as part of the Mandurah Ocean Marina precinct (Dunlop 2016). Over the past decade, fairy terns have attempted to nest on a number of estuarine islands (Boundary, Channel, Creery, Len Howard, and Mandurah Quay Islands) and at Nairns beach, near the mouth of the Serpentine River (Fig. 1). However, these nesting attempts have failed, primarily because of increased high tide levels and summer storm surge events (Dunlop 2016). In 2015-2016 and 2016-2017, nesting attempts were made on vacant development blocks within the Mandurah Ocean Marina Precinct. However, few chicks fledged, possibly as a result of high disturbance levels or predation (Dunlop 2018, Greenwell et al. 2019a, C. Corker pers. comm.)

In 2017, the Mandurah fairy tern breeding site was established to overcome a lack of secure, flood-free breeding sites available to fairy terns in the region. The site $\left(\sim 1500 \mathrm{~m}^{2}\right)$ has a uniform elevation of $\sim 3.0 \mathrm{~m}$ above sea level and is separated from the adjoining beach by a $\sim 1.5 \mathrm{~m}$ high limestone rock sea wall. The perimeter of the site is fully enclosed with chain-wire

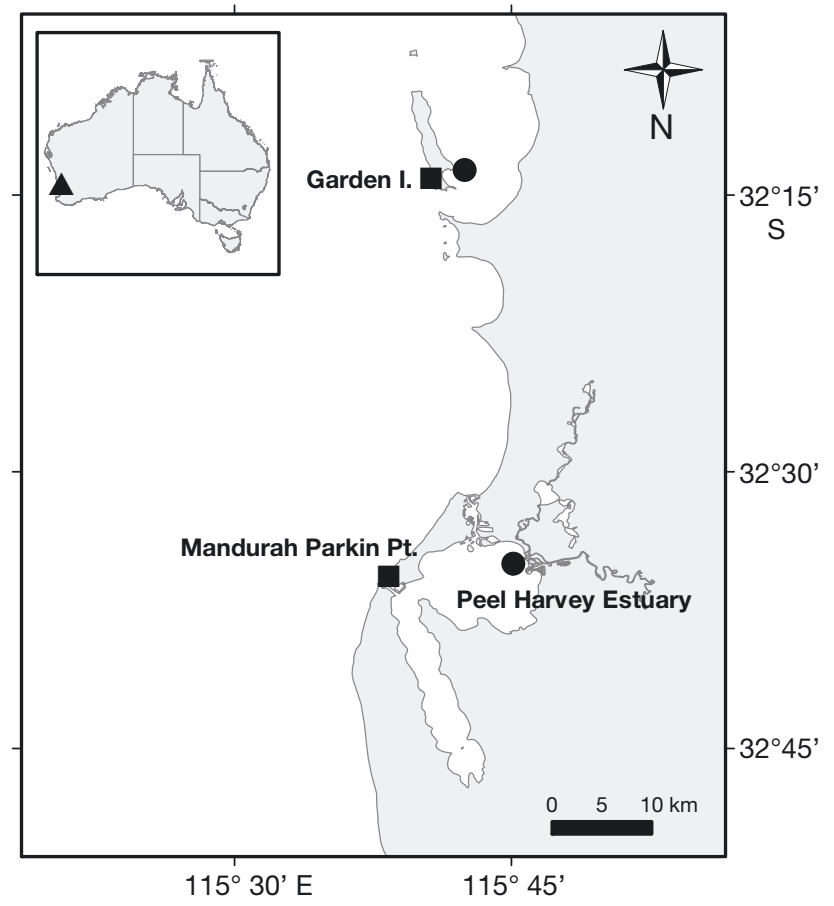

Fig. 1. Locations of study (ם) and historically important breeding (-) sites of Australian fairy tern Sternula nereis nereis along the south-western Australian coastline between 2018 and 2020 fencing lined with shade cloth. A layer of shell material was added to the ground surface by land managers to enhance its attractiveness to fairy terns. Black rats Rattus rattus were not detected in the area prior to the commencement of breeding but baits were deployed along the adjoining sea wall as a precautionary measure. During the 2017-2018 breeding season (October to January), decoys were deployed at the site in an attempt to attract mature breeding adults. Ad hoc observations indicated that the birds were not interested in the site, despite the presence of the decoys. On 2 October 2018, prior to the start of our study, adult fairy terns in advanced nuptial breeding plumage (i.e. solid black head cap and bright orange bills and legs, indicating readiness for breeding), were observed landing on the seawall and beach adjacent to the fairy tern site.

The second site was located at Garden Island $\left(32^{\circ} 14^{\prime} 31.92^{\prime \prime} \mathrm{S}, 115^{\circ} 41^{\prime} 36.3372^{\prime \prime} \mathrm{E}\right)$, which is on a Commonwealth military base (HMAS Stirling) managed by the Department of Defense. Garden Island is a historically important breeding site for fairy terns, with records of colonies at various locations across the island, including the Causeway, a traffic bridge that provides access to the island from the mainland (Higgins \& Davies 1996, Dunlop 2016). Reproductive success varies greatly from year to year. Occasionally, entire colonies are lost through colony inundation and egg burial during summer storms, and mortality arising from vehicle strike has been recorded when birds nest on the edge of the Causeway (Dunlop 2016, G. Davies pers. comm.). Garden Island has also been identified as an important pre-breeding night roost location for fairy terns (see Dunlop \& Greenwell 2021).

In 2018, a managed site was established on Garden Island for fairy terns in an attempt to improve breeding outcomes and discourage nesting on the Causeway. The site $\left(\sim 3500 \mathrm{~m}^{2}\right)$ has a uniform elevation of $\sim 3.0 \mathrm{~m}$ above sea level and is separated from the adjoining beach by a $\sim 1.5 \mathrm{~m}$ high, vegetated sand dune. A limestone rock wall, which adjoins a road, runs parallel to the dune along the entire length of the site on the opposite side. A layer of shell material was added to the ground surface by land managers to enhance its attractiveness to fairy terns. A baiting program was undertaken in 2019 after black rats were detected in the area, to reduce the potential for egg depredation. During the 2018-2019 breeding season (October-January), before this study commenced, decoys were deployed on the site; however, ad hoc observations indicate that no interest was shown by the terns. 


\subsection{Study design}

Conspecific call playback (audio cues) and decoys (visual cues) were used at Mandurah and Garden Island to determine whether these sensory-based cues increased the likelihood of attracting fairy terns to an area of potential nesting habitat. A crossover study design was adopted to measure the behavioral response of terns to different cues. This design consisted of all possible pairings of decoy and call playback treatments (control [no attractants], decoys only, call playback only, decoys and call playback), allocated as part of a random block design (Table 1).

The study was carried out between 06:15 and 08:15 h on 5-19 October 2018 and 7-30 October 2019 at Mandurah and Garden Island, respectively, corresponding with the typical prospecting and early egglaying period of fairy terns. Six 4 d blocks were planned for each site, but on 19 October 2018, a fairy tern was observed incubating an egg at the Mandurah site. As a result, the social facilitation treatment was stopped due to the need for the egg to be incubated, which would bias further observations. As a consequence, the behavioral response of fairy terns at Mandurah was limited to 3 full blocks.

The length of time that any individual from a group of terns spent (1) flying above the site or (2) on the ground was measured using 2 stopwatches to produce separate timing intervals for each activity. Timing commenced when terns either flew over or landed at the site. Stopwatches were left running for as long as any individual remained either over the site or on the ground, allowing the time interval of each landing and aerial prospecting event to be recorded separately. Observations of the maximum number of birds present and the duration of each landing or aerial prospecting event were made over a continuous 120 min observation period on consecutive days from a vantage point outside the study area.
Note that a lack of distinguishing features between birds precluded individuals being counted. The cumulative time that fairy terns spent on the ground (landing events) or in the air over the site (aerial prospecting events) each day was calculated for the 2 sites and is used as the sampling unit in this study.

\subsection{Decoys and audio recordings}

Models of least terns (Mad River Decoys, Audubon Society) were hand-painted to replicate the nuptial plumage of breeding adult fairy terns (Fig. 2). A conspecific vocalization recording, obtained from a fairy tern colony in Bunbury ( 120 km south of Mandurah) during the 2017-2018 breeding season, was edited using Wavepad software to increase its amplitude, remove silver gull Chroicocephalus novaehollindae vocalizations, and delete the first and last segment of the recording to ensure that only settled colony call playbacks were used. The recording ( 50 min long) was then loaded onto an MP3 player (Apple iPod) and set to loop.

Conspecific call playback was played using a $15 \mathrm{~W}$ Toa broadcast megaphone modified with an input socket for MP3 attachment. The megaphone was positioned at the edge of the study site in the surrounding vegetation, and call playbacks were projected up and over the site. On the days when the decoys $(n=10)$ were deployed, they were spaced $1.5 \mathrm{~m}$ apart in a combination of singles (6) and pairs (4) (Fig. 3) to reflect natural conditions observed within a colony (Burger 1988). A social experiment on the closely related least tern Sternula antillarum showed that terns were attracted to larger groups and preferred to land where decoys were more spaced out (1.5 vs. $0.5 \mathrm{~m})$, landing in the center of the group rather than the edge (Burger 1988). Singular decoys may provide a cue for single birds to settle and acquire mates, while established decoy pairs

Table 1. Cross-over study design to test the effectiveness of conspecific audio-visual cues (decoys and call playback) in attracting the Australian fairy tern Sternula nereis nereis to areas of potential nesting habitat in south-western Australia. Treatment groups (C: control; D: decoys; P: call playback; P + D: decoys and call playback) were allocated as part of a random block design. Start dates are provided for each $4 \mathrm{~d}$ block encompassing the 4 treatment groups. Dates are dd/mm/yy

\begin{tabular}{|c|c|c|c|c|c|c|c|c|c|}
\hline \multirow[t]{2}{*}{ Day } & \multirow[b]{2}{*}{ 05/10/18 } & \multirow{2}{*}{$\begin{array}{c}\text { Mandurah } \\
09 / 10 / 18\end{array}$} & \multirow{2}{*}{$13 / 10 / 18$} & \multirow[b]{2}{*}{ 07/10/19 } & \multirow[b]{2}{*}{$11 / 10 / 19$} & \multirow{2}{*}{\multicolumn{2}{|c|}{$\begin{array}{c}\text { Garden Island } \\
15 / 10 / 19 \quad 19 / 10 / 19\end{array}$}} & \multirow[b]{2}{*}{$23 / 10 / 19$} & \multirow[b]{2}{*}{$27 / 10 / 19$} \\
\hline & & & & & & & & & \\
\hline 1 & $P+D$ & $\mathrm{P}$ & D & $\mathrm{P}$ & C & D & $\mathrm{P}$ & C & C \\
\hline 2 & C & D & $\mathrm{P}$ & C & D & $\mathrm{P}$ & $P+D$ & $P+D$ & D \\
\hline 3 & $\mathrm{P}$ & $\mathrm{P}$ & C & $P+D$ & $\mathrm{P}$ & C & C & $\mathrm{P}$ & $\mathrm{P}$ \\
\hline 4 & D & $\mathrm{C}$ & $P+D$ & $\mathrm{D}$ & $P+D$ & $P+D$ & $\mathrm{D}$ & $\mathrm{D}$ & $P+D$ \\
\hline
\end{tabular}


may provide a cue for nest site selection and colony stability (Burger 1988, Arnold et al. 2011).

In 2018, removal of the decoys was hampered when fairy terns remained on the ground at the Mandurah site at the conclusion of the observation period. To minimize disturbance to birds prospecting the site, decoys were left in place until early the following morning and removed prior to the commencement of the observation period, when decoy treatments were not scheduled. At Garden Island in 2019 , the process of removing decoys early the following morning was repeated for consistency between the 2 sites. Wind speed and direction data, at 30 min intervals, were obtained from Bureau of Meteorology, and both average and maximum wind speed over the $2 \mathrm{~h}$ sampling period were calculated. In addition, the physical behavior of terns towards call playbacks and decoys was recorded in an ad hoc manner.

\subsection{Statistical analyses}

All statistical analyses were performed using R version 4.0.2 (R Core Team 2020). We investigated in separate analyses the relationship between (1) the time spent aerial prospecting and the 2 treatments (decoys and call playback) and (2) the maximum number of birds aerial prospecting and the 2 treatments. In both cases, we fitted multiple linear regression models which included the 2 treatments and site as dummy variables and average wind speed and maximum wind speed as continuous explanatory variables. These models considered all possible interactions between the 2 treatment variables and site as

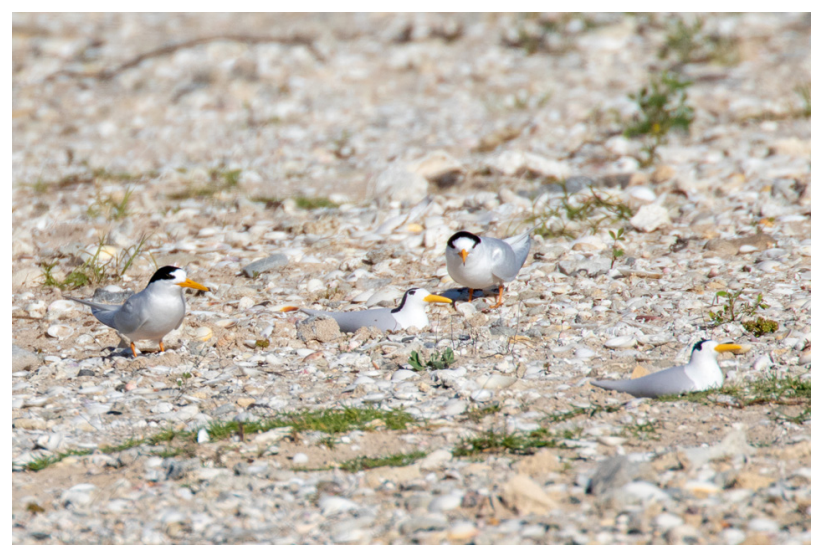

Fig. 2. Australian fairy terns Sternula nereis nereis interacting with 'incubating' decoys (painted plastic models) at the Mandurah managed breeding site, south-western Australia, in 2018

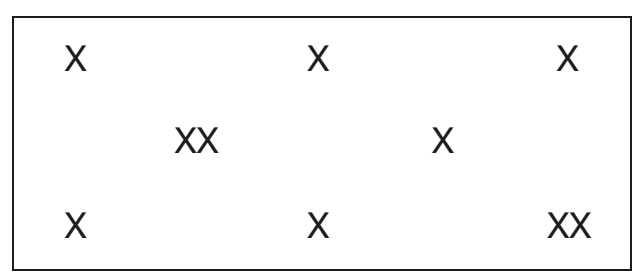

Fig. 3. Arrangement of decoys (' $\mathrm{X}$ ', placed as singles or pairs), spaced $1.5 \mathrm{~m}$ apart, at the managed Australian fairy tern Sternula nereis nereis breeding sites at Mandurah and Garden Island, south-western Australia

well as interactions between site and wind speed variables. Residual plots highlighted the need to transform the time spent aerial prospecting (square root transformation, as identified using the 'boxcox' function in the 'MASS' package in $\mathrm{R}_{i}$ Venables \& Ripley 2002) to produce greater compliance with the assumptions of linear regression. No transformation was required for the maximum number of birds aerial prospecting. Using the previously described explanatory variables and interactions, we performed an exhaustive model search to find the models minimizing second-order Akaike information criterion $\left(\right.$ AIC $_{C}$ Akaike 1974, Hurvich \& Tsai 1989) for each response variable (i.e. time spent aerial prospecting, maximum number of birds aerial prospecting). The 'AICcmodavg' package for R was used in calculating $\mathrm{AIC}_{\mathrm{C}}$ (Mazerolle 2020).

Birds landed on the site at Garden Island on only $1 \mathrm{~d}$ during the observation period, and only $12 \mathrm{~d}$ were recorded for landing time at Mandurah before a fairy tern was observed incubating an egg. Considering the small number of days for which there was any (non-zero) landing time data, our analysis of (1) landing time data and (2) maximum number of fairy terns observed on the ground and the relationship between these outcomes and the treatments is purely descriptive.

\section{RESULTS}

\subsection{Statistical models}

On average, the time fairy terns spent aerial prospecting or on landing events in treatments with call playbacks (either with or without the decoys) was greater than in the control and decoy-only treatments (Figs. 4 \& 5). However, there was substantially greater variability in time spent aerial prospecting at Mandurah relative to Garden Island, particularly in the call playback-only treatment. Fairy terns began aerial prospecting at both sites within 20 min of the 
first call playback treatments, and at Mandurah, terns began landing within $60 \mathrm{~min}$.

An exhaustive model search based on minimizing $\mathrm{AIC}_{\mathrm{C}}$ was carried out for the response of square root transformed aerial prospecting time using, as explanatory variables, the 2 treatment variables (decoys, call playback), site, average wind speed, maximum wind speed, all possible interactions between the treatment variables and site, and interactions between the wind speed variables. The model minimizing $\mathrm{AIC}_{\mathrm{C}}$ included the call playback treatment, site, maximum wind speed, a call playback treatment $\times$ site interaction, and a site $\times$ maximum wind speed interaction (Table 2, adjusted $\mathrm{R}^{2}=0.827$ ), and all of these terms, except the call playback treatment $\times$ site interaction, were in the top 5 models in terms of minimizing $\mathrm{AIC}_{\mathrm{C}}$ (Tables S1 \& S2 in the Supplement at www.intres.com/articles/suppl/n045p147_supp.pdf). For this model, there was an estimated increase of $3.00 \mathrm{~min}$ $(95 \% \mathrm{CI}=0.58,7.29)$ in time spent aerial prospecting when call playback was used on Garden Island, controlling for maximum wind speed. No real call playback effect was evident for Mandurah, however, with an estimated call playback effect of $-0.57 \min (95 \%$
$\mathrm{CI}=-10.85,9.70)$ on the square root scale due to the call playback treatment $\times$ site interaction essentially negating the single-term call playback effect.

A similar exhaustive model search based on minimizing $\mathrm{AIC}_{\mathrm{C}}$ but using the maximum number of fairy terns prospecting as the response variable led to selection of a model that included single terms for the call playback treatment, site, and average wind speed variables, a call playback treatment $\times$ site interaction, and a site $\times$ average wind speed (Table 3 , adjusted $\mathrm{R}^{2}=0.848$ ). Site, average wind speed variables, and a site $\times$ average wind speed were in each of the top 5 models based on minimizing $\mathrm{AIC}_{\mathrm{C}}$, with the call playback treatment appearing in 3 of these (Tables S3 \& S4). For the model minimizing $\mathrm{AIC}_{\mathrm{C}}$ (Table 3), there was an estimated increase of 2.41 $(95 \% \mathrm{CI}=0.31,4.51)$ birds aerial prospecting when call playback was used on Garden Island, controlling for average wind speed. Again, however, there did not appear to be a real call playback effect for Mandurah (estimated decrease of -1.04 birds; $95 \%$ CI = $-4.03,1.94)$, with the call playback treatment $\times$ site interaction again essentially negating the singleterm call playback effect.

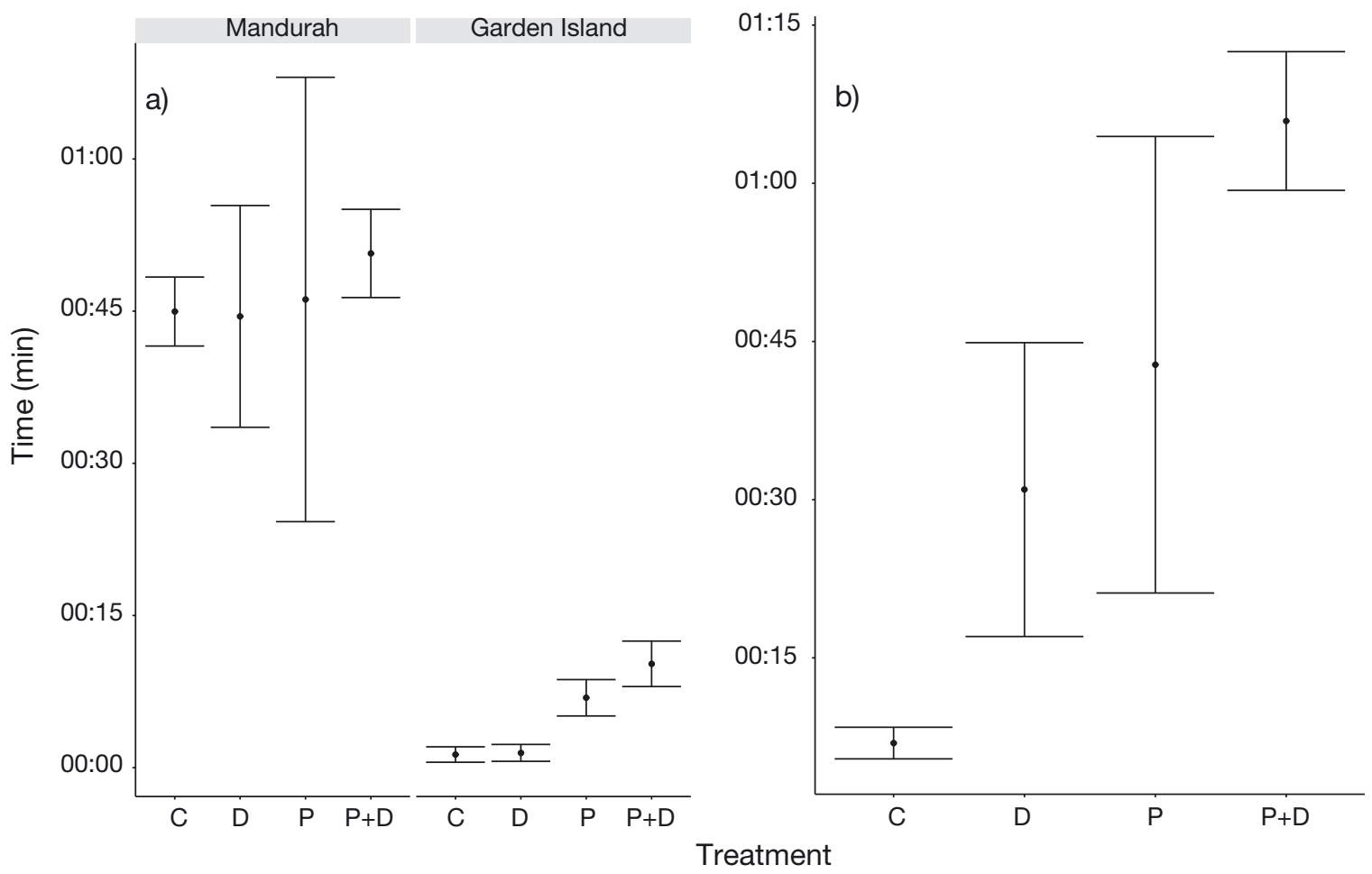

Fig. 4. Behavioral response of the Australian fairy tern Sternula nereis nereis to conspecific audio-visual cues at a potentially suitable nesting site at Mandurah (2018) and Garden Island (2019) in different treatments: mean ( \pm 1 SE) cumulative time spent (a) aerial prospecting at both sites and (b) on the ground at Mandurah. C: control; D: decoys, P: call playback; P + D: call playback and decoys 

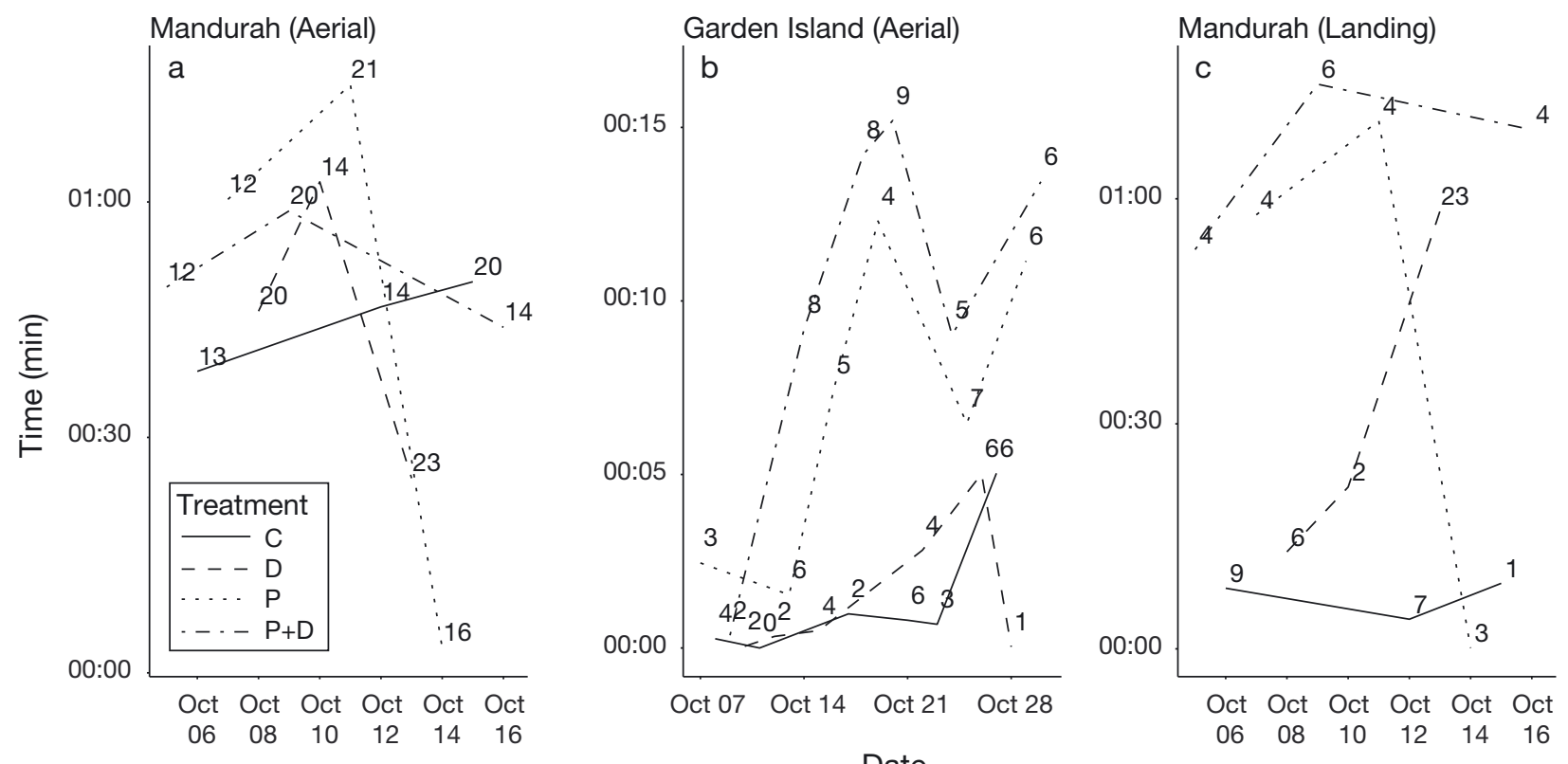

Fig. 5. Behavioral response of the Australian fairy tern Sternula nereis nereis to conspecific audio-visual cues. Points represent the total time (min) spent (a) aerial prospecting at Mandurah; (b) aerial prospecting at Garden Island; and (c) on the ground at Mandurah, during a $2 \mathrm{~h}$ observation period in response to one of 4 different treatments (C: control; D: decoys; P: call playback; P + D: call playback and decoys). Labels above points: maximum number of birds present at any one time during the observation period

\subsection{Mandurah}

The time spent aerial prospecting over Mandurah increased between the first and second treatment blocks for all treatments (Fig. 5a). During the third treatment block, this increase was followed by a sharp decline. The decline in aerial prospecting co-

Table 2. Model fit for a multiple linear regression of time spent aerial prospecting (square root transformed) on the treatments of call playback, site, maximum wind speed, an interaction $(x)$ between the call playback and site variables, and an interaction between the maximum wind speed and site variables $(n=36)$. Significant results are in bold $(p<0.05)$

\begin{tabular}{|lrrcc|}
\hline Variable & Estimate & SE & \multicolumn{1}{c}{$t$} & $\mathrm{p}$ \\
\hline Intercept & 14.108 & 9.886 & 1.427 & 0.164 \\
Call playback & 13.417 & 3.672 & 3.654 & $\mathbf{0 . 0 0 1}$ \\
Site (Mandurah) & 1.387 & 14.743 & 0.094 & 0.926 \\
Max. wind speed & -0.118 & 0.162 & -0.728 & 0.473 \\
Interactions & & & & \\
$\quad$ Call playback $\times$ & -13.990 & 6.228 & -2.246 & $\mathbf{0 . 0 3 2}$ \\
$\quad$ site (Mandurah) & & & & \\
$\quad$ Max. wind speed $\times$ & 0.777 & 0.250 & 3.108 & $\mathbf{0 . 0 0 4}$ \\
$\quad$ site (Mandurah) & & & & \\
Adjusted R ${ }^{2}$ 0.8271 & & & & \\
\hline
\end{tabular}

incided with a cold front producing $\sim 32 \mathrm{~km} \mathrm{~h}^{-1}$ winds and rainy conditions on 14 October (call playback), and there was an increase in the time spent on the ground on 16 October (playbacks and decoys).

Fairy terns spent an average ( $\pm 1 \mathrm{SE})$ of $65.9 \pm 6.6$ and $42.8 \pm 21.6 \mathrm{~min}$ on the ground in response to the call playback plus decoy treatment and call playback treatment, respectively (Figs. $4 \mathrm{~b} \& 5 \mathrm{c}$ ). In comparison, terns spent an average of $31.0 \pm 13.9$ and $6.9 \pm$ $1.5 \mathrm{~min}$ on the ground in response to decoy and control treatments, respectively (Fig. $4 \mathrm{~b}$ ). When decoys were in $s i t u$, fairy terns were observed interacting with the models (Fig. 2), and terns were regularly observed walking towards or flying above the speaker when call playbacks were broadcast.

On 19 October 2018, a fairy tern was observed incubating an egg on the Mandurah site. The colony grew steadily in size over several weeks, and the site went on to support a colony that peaked at 110 nests in late November 2018 (Greenwell et al. 2019a). While decoys remained in situ, no further call playback was used following the laying of the first egg. A second colony of terns was established on a beach $\sim 50 \mathrm{~m}$ away from the managed site on 30 October and peaked at $\sim 40$ nests in late November 2018 (Greenwell et al. 2019a). 
Table 3. Model fit for a multiple linear regression of maximum number of birds aerial prospecting on the treatment of call playback, site, average wind speed, an interaction $(x)$ between the call playback and site variables, and an interaction between the average wind speed and site variables. $(\mathrm{n}=36)$

\begin{tabular}{|lrccr|}
\hline Variable & Estimate & SE & \multicolumn{1}{c}{$t$} & $\mathrm{p}$ \\
\hline Intercept & 0.445 & 5.522 & 0.081 & 0.936 \\
Call playback & 2.415 & 1.029 & 2.348 & 0.026 \\
Site (Mandurah) & 30.508 & 7.048 & 4.328 & $<0.001$ \\
Ave. wind speed & 0.156 & 0.295 & 0.528 & 0.602 \\
Interactions & & & & \\
$\quad$ Call playback $\times$ & -3.458 & 1.787 & -1.935 & 0.062 \\
$\quad$ site (Mandurah) & & & & \\
$\quad$ Ave. wind speed $\times$ & -1.324 & 0.470 & -2.819 & 0.008 \\
$\quad$ site (Mandurah) & & & & \\
Adjusted R ${ }^{2}$ 0.8477 & & & & \\
\hline
\end{tabular}

\subsection{Garden Island}

On average, terns spent more time aerial prospecting over the site when call playback was used than the control or decoy-only treatments at Garden Island (Figs. 4a \& 5b). Unlike Mandurah, fairy terns only landed on the Garden Island site on a single day - birds landed amongst the decoys during the playback plus decoy treatment on 20 October 2019, when 2 or 3 birds landed on 3 occasions for 15, 21, and $40 \mathrm{~s}$. However, terns landed on the adjacent beach on $6 \mathrm{~d}(14,16,18,19,24$, and 29 October) when call playbacks were used, and this location was close to the speaker. No landing events were recorded on control or decoy treatment days. Terns regularly hovered over the speaker projecting the call playback and were observed making low flights over the decoys when in situ.

Terns spent an average of $10.2 \pm 2.32$ and $6.9 \pm$ 1.8 min flying over the site when call playback plus decoy and call playback-only treatments were used, respectively (Fig. 4a). In contrast, terns spent an average of $1.5 \pm 0.8$ and $1.3 \pm 0.8 \mathrm{~min}$ over the site on decoy-only and control days, respectively (Fig. 4a). There was a general increasing trend in the time spent prospecting over the study period, except in block 5 when strong winds $\left(33 \mathrm{~km} \mathrm{~h}^{-1}\right)$ were recorded on 24 October (call playback plus decoy) and on 25 October during the call playbackonly treatment. A decrease in the time spent at the site was also observed in block 6 during the decoy treatment (Fig. 4).

Fairy terns did not establish a colony at the Garden Island managed site during or after the study period.
Instead, the birds selected an alternative and historically important breeding site on Parkin Point, an expansive sandbar $\sim 800 \mathrm{~m}$ away from the managed site. The first colony on Parkin Point failed, likely due to egg depredation by black rats and possibly ghost crabs Ocypode sp., as animal tracks of these species were found around fairy tern nests. However, fairy terns formed a second colony on an alternative part of the sandbar protected by coastal vegetation, and following rodenticide baiting, the site went on to support a breeding colony of an estimated $\sim 145$ pairs that peaked in mid- to late January 2020.

\section{DISCUSSION}

While settling decisions by prospecting fairy terns varied between the 2 study sites, the audio-visual cues elicited a strong behavioral response at previously unused areas and resulted in egg laying at Mandurah. Overall, treatments with call playbacks stimulated a stronger behavioral response than decoy-only or control treatments. Active colonies provide information to prospecting birds about habitat suitability and the potential for individual breeding success (Reed \& Dobson 1993, Boulinier et al. 1996, Danchin et al. 1998). Therefore, the use of audio-visual cues (particularly call playbacks) that mimicked active breeding colony sounds provided an opportunity to influence fairy tern behavior (Friesen et al. 2017). For species such as fairy terns that breed in relatively ephemeral habitats, exhibit low site tenacity, and tend to periodically shift colony sites (Greenwell et al. 2021, Dunlop \& Greenwell 2021), social cues may be strong drivers of site selection (Burger 1984, Medeiros et al. 2012).

The results of this study, while limited in extent, appear consistent with those of Arnold et al. (2011), who also highlighted the importance of call playbacks compared to decoys for attracting common terns in Massachusetts, USA. They suggested that 'decoys are likely to be a secondary cue signaling the presence of breeding conspecifics only in the presence of sound' (Arnold et al. 2011, p. 498). Decoys deployed at Mandurah and Garden Island in the years prior to this study failed to attract prospecting fairy terns (see Section 2.1), yet birds began actively prospecting these sites within 20 min of call playbacks being used, supporting the premise that call playbacks are the primary cues needed to attract terns.

The results of the current study are in contrast to those of Jeffries \& Brunton (2001), who found that 
decoys attracted a significant behavioral response from New Zealand fairy terns Sternula nereis davisae, with or without playbacks. The reasons for the observed behavioral differences between the 2 subspecies remain unclear, although decoy design and the origin and type of conspecific call recordings used in the experiments may be important (see below). The differences in responses to artificial social facilitation between subspecies highlight the importance of assessing species-specific responses when efforts to improve reproductive success are required (reviewed by Friesen et al. 2017).

Marked differences in the time spent prospecting, settling behavior, and colony site selection were observed between the 2 sites at Mandurah and Garden Island. We propose 4 possible factors that may have contributed to these differences: reproductive phase, habitat availability, past breeding experience at other suitable sites, and the influence of group adherence behavior. During the pre-breeding period, attachment to potential colony sites is low, and prospecting bouts may be limited to a few birds visiting for brief periods before dispersing (Greenwell et al. 2021). Over time, terns may begin alighting and engaging in site-attachment activities such as territory establishment and scraping (Dunlop 1987, Kress 1997, Greenwell et al. 2021), but the timing of breeding likely coincides with a peak in prey availability (Monaghan et al. 1989, Zuria \& Mellink 2005, Paillisson et al. 2007). The rapid settling behavior at Mandurah, while unusual, may have been driven by individuals in an advanced reproductive stage, who were already utilizing a beach for courtship within close proximity $(\sim 50 \mathrm{~m})$ of the site just before the study period (C. N. Greenwell pers. obs.).

Conversely, at Garden Island, it is possible that terns were less advanced in their reproductive condition than those observed in Mandurah 1 yr earlier or that their fish prey was not sufficiently abundant. At Garden Island in 2019, the number of breeding pairs peaked in mid- to late January 2020 compared to a peak in late November in Mandurah in 2018. The timing of breeding varies widely between individuals, and food availability in the lead-up to the breeding period has the potential to affect the timing and success of reproduction (Regehr \& Rodway 1999, Zuria \& Mellink 2005, Kitaysky et al. 2007).

At Mandurah, the managed site is located within a historically important breeding area that has since been developed into a marina, and terns have periodically nested on empty blocks adjacent to the managed site. Therefore, strong area knowledge and historical use, along with social stimuli and conspecific cueing associated with previous experience may have contributed to a stronger response by fairy terns already prospecting in the area (Boulinier et al. 1996). On Garden Island, alternative habitat, i.e. a large sandbar (Parkin Point), located $\sim 800 \mathrm{~m}$ away that is also used as a night roost, may have contributed to the terns on the island ultimately selecting this site and showing less interest in the prepared managed site.

Finally, the origin of call playbacks obtained for this study may have contributed to the terns ultimately selecting the alternative site at Garden Island. Group adherence and the maintenance of strong alliances between groups of birds is, potentially, an important behavioral trait among fairy terns (Dunlop \& Greenwell 2021), as has been shown for least terns and common terns (Austin 1951, Atwood \& Massey 1988). Playback experiments performed in a least tern colony in North Carolina showed that the temporal and spectral characteristics of calls varied significantly between individuals, enabling the identification of mates (Moseley 1979). The individual recognition of associates and group adherence behavior may, therefore, be an important cue in encouraging site selection, particularly during the early stages of colony formation. Further research is required to elucidate whether the behavioral response of small terns varies according to the origin of the playback call. That is, can the calls of birds from one region be used to successfully encourage settlement of birds from another region or state, and do locally sourced colony calls lead to increased settlement? It is also possible that different decoy designs, such as recently developed, 3D-printed fairy tern models (www.shaunlee.co.nz) and model eggs (visual cues), may influence the behavior of terns, which are topics for future research. Anecdotal observations of early colony formation in fairy terns indicate that the presence of eggs may provide a strong stimulus for prospecting individuals (C. N. Greenwell pers. obs.).

Social facilitation and the stimuli acting on gregarious species such as the fairy tern have the potential to influence colony establishment but may be dependent on a range of interacting factors. While fairy terns did not select the Garden Island managed site for nesting, this site has the potential to be occupied in subsequent breeding seasons with further artificial social facilitation. It is important to note that call playback was only utilized on $2 \mathrm{~d}$ within a $4 \mathrm{~d}$ block and was limited to a $2 \mathrm{~h}$ period in the morning over $24 \mathrm{~d}$ at this site. In a restoration project involving Arctic terns and common terns, call playbacks were broadcast for 3 yr before a colony was formed (Kress 
1983). Sightings of terns increased 2 -fold within the first year of using call playbacks and decoys, and despite not actively nesting on the site, terns were seen interacting with decoys and made nest scrapes in the area of the decoys (Kress 1983). By the third year of using these attractants, a mixed colony of Arctic and common terns formed (80 pairs) around the decoys and speaker, with some of the early colonizers establishing nests $<10 \mathrm{~cm}$ from decoys (Kress 1983).

The behavioral response of fairy terns to artificial social facilitation over a relatively short period highlights the potential for call playback and, to a lesser extent, decoys to be used as a tool to encourage site selection by increasing social stimuli (Kress 1983). However, due to an absence of past experience at newly created sites, social facilitation may be required over several breeding seasons before colonies are established (Kress 1983, 1997). This may include the use of decoys and broadcasting call playbacks for at least several hours per day, particularly in the mornings when site prospecting activity is high (Dunlop 1987, Greenwell et al. 2021).

Site selection and the associated site threat profiles should be given careful consideration before social facilitation is undertaken to reduce the potential for terns to be attracted into ecological traps or suboptimal habitats (Battin 2004, Ward et al. 2011). While habitats may provide the fundamental conditions necessary to encourage site selection, the inability of land managers to adequately mitigate the external influences that limit reproductive success may lead to reproductive failure (Ward et al. 2011, Greenwell et al. 2019a).

Increased anthropogenic pressures, including coastal development, have the potential to fundamentally change coastal processes and the habitats that support birdlife. In some locations, dedicated managed sites may offer long-term solutions for coastal birds like fairy terns. Managed sites such as North Fremantle (see Greenwell et al. 2019b) show the potential of dedicated nesting areas to maintain breeding aggregations and support reproductive success by overcoming a lack of natural habitat. However, regular monitoring and management of site threat profiles to support the target species remain critical (Commonwealth of Australia 2019).

The maintenance and establishment of multiple sites, whether natural or artificially created, in areas of high human activity, is important. The availability of multiple sites will allow for periodic shifting of colony locations over the years in response to changes in site suitability (e.g. food availability, habi- tat stability, disturbance, predation), which is an important behavioral characteristic of fairy terns (Greenwell et al. 2020, Dunlop \& Greenwell 2021).

Acknowledgements. We acknowledge the traditional owners of the Binjareb and Whadjuk Noongar country, upon whose lands we had the great privilege of conducting this research. We extend our sincere thanks to members of the Western Australian Fairy Tern Conservation Network, including Alanna Smith, Alanna Wonders, Barbara Manson, Barbara Sing, Bel Matthews, Brett Newmarch, Caitlan Davis, Cherilyn Corker, Clara Obregon Lafuente, Elly Bentley, Jo Drew, Jorja Claybrook, Julie Knight, Kara Price, Kathleen Broderick, Maggie Duggan, Mal Beeton, MaryAnn Rath, Peter Moore, Phil Auty, Phillip Moll, Robyn Bickell, Serin Sabaraj, Susie Stockwell, and Tahlia Jones, who generously gave their time to assist with this research. We thank Rebecca Cassells and the City of Mandurah for their support and championing fairy tern management in the Mandurah region. To Georgia Davies, Kara Price, Mark Sweetman, and Department of Defence staff at HMAS Stirling, thank you for your efforts to improve breeding outcomes for fairy terns on Garden Island. Thank you to Mike Calver for advice on the experimental design. Financial support for this project was provided by Stuart Leslie Bird Award \& BirdLife Australia and the Holsworth Wildlife Research Endowment \& Ecological Society of Australia. We are extremely grateful to the reviewers and handling editor, who provided constructive feedback to improve the manuscript. Financial support to C. N. Greenwell was received through an Australian Government Research Training Program Scholarship. This research was conducted in accordance with Murdoch University Animal Ethics approval (Permit R3077/18).

\section{LITERATURE CITED}

Akaike H (1974) A new look at statistical model identification. IEEE Trans Automat Contr 19:716-723

Arnold JM, Nisbet ICT, Veit R (2011) Assessing aural and visual cueing as tools for seabird management. J Wildl Manag 75:495-500

Atwood JL, Massey BW (1988) Site fidelity of least terns in California. Condor 90:389-394

Austin OL (1951) Group adherence in the common tern. Bird-Banding 22:1-15

Battin J (2004) When good animals love bad habitats: ecological traps and the conservation of animal populations. Conserv Biol 18:1482-1491

BirdLife International (2018) Fairy tern, Sternula nereis. The IUCN Red List of Threatened Species 2018:e.T22694691A132568135. https://dx.doi.org/10.2305/IUCN.UK.20182.RLTS.T22694691A132568135.en (accessed 6 August 2019)

Boulinier T, Danchin E, Monnat JY, Doutrelant C, Cadiou B (1996) Timing of prospecting and the value of information in a colonial breeding bird. J Avian Biol 27:252-256

Burger J (1984) Colony stability in least terns. Condor 86: 61-67

Burger J (1988) Social attraction in nesting least terns: effects of numbers, spacing, and pair bonds. Condor 90:575-582

Cody ML (1985) Habitat selection in birds. Academic Press, London 
Commonwealth of Australia (2019) Draft National Recovery Plan for the Australian fairy tern (Sternula nereis nereis). https://www.environment.gov.au/biodiversity/threatened/ recovery-plans/comment/draft-recovery-plan-australianfairy-tern

Danchin E, Boulinier T, Massot M (1998) Conspecific reproductive success and breeding habitat selection: implications for the study of coloniality. Ecology 79:2415-2428

Dunlop J (1987) Social behavior and colony formation in a population of crested terns, Sterna bergii, in southwestern Australia. Aust Wildl Res 14:529-540

Dunlop JN (2016) Local fairy tern conservation strategy for the south west coastal region. Conservation Council of Western Australia, Perth

Dunlop JN (2018) Fairy tern (Sternula nereis) conservation in south-western Australia, $2^{\text {nd }}$ edn. Conservation Council of Western Australia, Perth

Dunlop JN, Greenwell CN (2021) Seasonal movements and meta-population structure of the Australian fairy tern in Western Australia. Pac Conserv Biol 27:47-60

Friesen MR, Beggs JR, Gaskett AC (2017) Sensory-based conservation of seabirds: a review of management strategies and animal behaviours that facilitate success. Biol Rev Camb Philos Soc 92:1769-1784

Fujita G, Totsu K, Shibata E, Matsuoka Y and others (2009) Habitat management of little terns in Japan's highly developed landscape. Biol Conserv 142:1891-1898

Gochfeld M (1980) Mechanisms and adaptive value of reproductive synchrony in colonial seabirds. In: Burger J, Olla BL, Winn HE (eds) Behavior of marine animals. Springer, Boston, MA, p 207-270

Gochfeld M, Burger J (1992) Family Sternidae (terns). In: Hoyo J del, Elliott A, Sargatal J, Cabot J (eds) Handbook of the birds of the world. Lynx Edicions, Barcelona, p 624-667

* Greenwell CN, Calver MC, Loneragan NR (2019a) Cat gets its tern: a case study of predation on a threatened coastal seabird. Animals (Basel) 9:445

Greenwell CN, Dunlop JN, Loneragan NR (2019b) Nest desertion: an anti-predator strategy of the Australian fairy tern, Sternula nereis nereis. Mar Ornithol 47:197-201

*Greenwell CN, Dunlop JN, Admiraal R, Loneragan NR (2021) The secret life of fairy terns: breeding chronology and life history observations of Sternula nereis nereis in south-western Australia. Pac Conserv Biol 27:143-154

Hecht A, Melvin SM (2009) Expenditures and effort associated with recovery of breeding Atlantic coast piping plovers. J Wildl Manag 73:1099-1107

Higgins P, Davies SJJF (1996) Handbook of Australian, New Zealand and Antarctic birds, Vol 3: snipe to pigeons. Oxford University Press, Melbourne

Hurvich CM, Tsai CL (1989) Regression and time series model selection in small samples. Biometrika 76:297-307

James MS, Stockwell MP, Clulow J, Clulow S, Mahony MJ (2015) Investigating behaviour for conservation goals: conspecific call playback can be used to alter amphibian distributions within ponds. Biol Conserv 192:287-293

Jeffries DS, Brunton DH (2001) Attracting endangered species to 'safe' habitats: responses of fairy terns to decoys. Anim Conserv 4:301-305

Jenniges JJ, Plettner RG (2008) Least tern nesting at human

Editorial responsibility: Rory Wilson,

Swansea, UK

Reviewed by: 3 anonymous referees created habitats in central Nebraska. Waterbirds 31: 274-282

Johnstone RE, Storr GE (1998) Handbook of Western Australian birds, Vol 1: non passerines, emu to dollarbird. Western Australian Museum, Perth

Kitaysky AS, Piatt JF, Wingfield JC (2007) Stress hormones link food availability and population processes in seabirds. Mar Ecol Prog Ser 352:245-258

Kress SW (1983) The use of decoys, sound recordings, and gull control for a tern colony in Maine. Colon Waterbirds 6:185-196

Kress SW (1997) Using animal behavior for conservation: case studies in seabird restoration from The Maine Coast, USA. J Yamashina Inst Ornithol 29:1-26

Kress SW, Nettleship DN (1988) Re-establishment of Atlantic puffins (Fratercula arctica) at a former breeding site in the Gulf of Maine. J Ornithol 59:161-170

*Mazerolle MJ (2020) AICcmodavg: model selection and multimodel inference based on (Q)AIC(c). R package version 2.3-1. https://cran.r-project.org/package=AICcmodavg

* Medeiros R, Ramos JA, Pedro P, Thomas RJ (2012) Reproductive consequences of nest site selection by little terns breeding on sandy beaches. Waterbirds 35:512-524

*Monaghan P, Uttley JD, Burns MD, Thaine C, Blackwood J (1989) The relationship between food supply, reproductive effort and breeding success in Arctic terns Sterna paradisaea. J Anim Ecol 58:261-274

Moseley LJ (1979) Individual auditory recognition in the least tern (Sterna albifrons). Auk 96:31-39

* Paillisson JM, Reeber S, Carpentier A, Marion L (2007) Reproductive parameters in relation to food supply in the whiskered tern (Chlidonias hybrida). J Ornithol 148:69-77

* Pakanen VM, Hongell H, Aikio S, Koivula K (2014) Little tern breeding success in artificial and natural habitats: modelling population growth under uncertain vital rates. Popul Ecol 56:581-591

R Core Team (2020) R: a language and environment for statistical computing. R Foundation for Statistical Computing, Vienna

Keed JM, Dobson AP (1993) Behavioural constraints and conservation biology: conspecific attraction and recruitment. Trends Ecol Evol 8:253-256

Regehr HM, Rodway MS (1999) Seabird breeding performance during two years of delayed capelin arrival in the northwest Atlantic: a multi-species comparison. Waterbirds 22:60-67

Venables WN, Ripley BD (2002) Modern applied statistics with $S, 4^{\text {th }}$ edn. Springer, New York, NY

WWard MP, Semel B, Jablonski C, Deutsch C, Giammaria V, Miller SB, McGuire BM (2011) Consequences of using conspecific attraction in avian conservation: a case study of endangered colonial waterbirds. Waterbirds 34: 476-480

*Yasué M, Patterson A, Dearden P (2007) Are saltflats suitable supplementary nesting habitats for Malaysian plovers Charadrius peronii threatened by beach habitat loss in Thailand? Bird Conserv Int 17:211-223

Zuria I, Mellink E (2005) Fish abundance and the 1995 nesting season of the least tern at Bahía de San Jorge, Northern Gulf of California, México. Waterbirds 28:172-180

Submitted: September 16, 2020

Accepted: March 19, 2021

Proofs received from author(s): June 2, 2021 